\title{
International Journal of Nanotechnology in Medicine
} \& Engineering

ISSN 2474-8811

Research Article

Open Access

Green Synthesis of Silver Nanoparticles and Evaluation of its Potential for Decolourization of a Synthetic Dye and Antibacterial Activity

Teklit Gebregiorgis Amabye' ${ }^{1}$ Kiros Hagos ${ }^{2}$

Department of Chemistry, Mekelle University, Mekelle, Tigray Ethiopia

State Key Laboratory of Materials-Oriented Chemical Engineering, Nanjing Tech University, Nanjing 210009, China.'

Corresponding Author: Teklit Gebregiorgis Amabye, Department of Chemistry, Mekelle University, Mekelle, Tigray

Ethiopia. Email: teklitgeb@gmail.com Tel No.: +251344407608;

Citation: Teklit Gebregiorgis Amabye, et.al (2017) Green Synthesis of Silver Nanoparticles and Evaluation of its Potential for Decolourization of a Synthetic Dye and Antibacterial Activity. Int J Nano Med \& Eng. 2:7, 120-126.

Copyright: (C) 2017 Teklit Gebregiorgis Amabye. This is an open-access article distributed under the terms of the Creative Commons Attribution License, which permits unrestricted use, distribution, and reproduction in any medium, provided the original author and source are credited.

Received April 18, 2017 Accepted May 022017 Published August 07, 2017

Abstract

In the present study, AgNPs were synthesized by employing an eco-friendly and convenient method using cell free supernatant of a isolated bacterial strain $\mathrm{AN}-1$, Bacterial proteins were used as a reducing agent for the synthesis of silver nanoparticles from silver nitrate $\left(\mathrm{AgNO}_{3}\right)$. Biosynthesis of silver nanoparticles was substantiated by the occurrence of surface Plasmon peak of silver nanoparticles at $405 \mathrm{~nm}$. FTIR analysis of AgNPs re-vealed the structure and the signature bands of the bio-synthesized nanoparticles, at 2,966, 1,636, and $1,403 \mathrm{~cm}^{-1}$. Further characterization with SEM analysis revealed the spherical, polydisperse AgNPs of particle size ranging from 74.56 to $92.67 \mathrm{~nm}$. Biosynthesized AgNPs showed significant antimicrobial activity and dye decolorizing ability. Study affirmed that the nanoparticles synthesized by bacteria can be utilized as promising agents for antibacterial applications and treatment of synthetic dyes.

Keywords: Silver nanoparticles; Spherical; Decolourization; Antibacterial Synthetic Dyes

\section{Introduction}

With unique physical chemical and biological peculiarities, nanotechnology has emerged as a science rendering great contribution in the development and expansion of Science and Technology ${ }^{[1]}$. Noble metallic nanoparticles differ from bulk material and have peculiar optical, mechanical, electronic, magnetic and chemical properties ${ }^{[2]}$. Nanomaterials have been used in several electronic applications, commercial products, medical instruments, textiles, cosmetics ${ }^{[3,4]}$.

Unremitting increase in multidrug - resistant human pathogenic microbes in environment has emerged as a serious med-icosocial problem worldwide. Such microbes cause increased number of mortality, morbidity and cost of prolonged treatments. It is therefore, exigent to develop, modify and explore novel antimicrobial compounds having bactericidal potential against MDR bacteria. Silver Nanoparticles have emerged as a promising tool in pharmaceutical and biomedical sector due to their inhibitory effect towards many bacterial strains in general and multidrug resistant bacteria particular ${ }^{[5]}$. Besides possessing antibacterial prop-erty, silver nanoparticles (AgNPs) happens to be good conductor, catalysts, antifungal agents, antiviral agents and antiinflammatory in nature and is known to be used in several well documented applications ${ }^{[6]}$. Silver nanoparticles have the potential to efficiently interact with biomolecules both on the surface and inside the body cells, which may bring revolution in diagnosis and treatment of many infectious diseases ${ }^{[7-9]}$. Because of high catalytic efficiency, higher surface area, mass transfer effect, and high surface reaction activity ${ }^{[10]}$, Nanotechnology also facilitates the application of wide spectrum of nanoparticles as catalyst in waste water treatment process ${ }^{[11]}$.

The industries like textile and leather release huge amounts of synthetic dyes in general and azo dyes in particular into aqueous streams. More than 2000 structurally different azo dyes are being used by these industries. In order to treat coloured waste water, different physico-chemical strategies such as adsorption and chemical treatment, ion exchange are being employed ${ }^{[12]}$. Such processes are not cost effective and generate huge amount of toxic intermediates and sludge thereby producing secondary pollutants Several research attempts are being made to overcome such problems by resorting to biological methods which are eco- 
friendly and cost effective. Nano-bioremediation technology has been developed to facilitate the bioremediation of organic pollutants including synthetic dyes, which involves the use of nanoparticles to enhance bioremediation ${ }^{[13]}$.

There are different physic-chemical approaches to synthesize nanomaterials for aforesaid applications which include electrochemical, microwave, thermal decomposition, etc. These methods employ undesirable chemicals leading to formation of toxic intermediates. Some of these processes also have problems with the stability, controlled crystal growth and aggregation of nanosize particles. In recent years, green synthesis of nanomaterials in general and synthesis of nanomaterial by employing biological meth-ods in particular has been recognized as a potential means of nanosynthesis ${ }^{[14]}$. Biologically produced nanoparticles are being exten-sively used in diverse applications, like intercalating materials in electric batteries, coatings on solar energy absorption, biolabelling, bioleaching, catalysis in chemical reactions and also as biomedical agents ${ }^{[15]}$.

In the present study an attempt has been made towards microbial synthesis of silver nanoparticles from bacteria isolated from organic pollutant contaminated site and further evaluation of its potential in antimicrobial activity and dye bleaching. Micro-bial production of silver nano-particles was investigated using the isolated bacterial strain as a reducing agent; this research work implies the production of silver nanoparticles, their characterization and evaluation of potential in dye bleaching and inhibitory action against another isolated bacterial species.

\section{Materials and Methods}

AgNO3 and bacterial growth medium Nutrient broth ( $\mathrm{N}$ broth) was procured from Hi-media laboratories, Mumbai, India. Mili Q (Millipore) de-ionized water was used in over all experiment.

\section{Isolation and characterization of bacteria}

Soil samples polluted with organic pollutants were collected in sterile plastic bags. Collected samples were serially diluted up to the level of $10^{-2}, 10^{-3}, 10^{-4}, 10^{-5}$ and $10^{-6}$. Aliquots of $0.1 \mathrm{ml}$ suspension were spread on plates poured with nutrient agar medium.

The bacterial colonies appeared were purified by repeated streaking. The purified bacterial strains were strains were maintained on nutrient agar slants and stored at $40 \mathrm{C}$ in a refrigerator for further experiments. The isolated bacterial strains were microscopically ob-served for shape and Gram reaction. The bacterial growth profile of isolated bacteria was studied using nutrient broth medium. The isolated bacterial strains were inoculated into broth medium and O.D of the culture was consistently recorded at $650 \mathrm{~nm}$ at regular intervals. $\mathrm{AgNO}_{3}$ tolerance profile was assessed by incubating the bacterial culture in nutrient broth medium containing different concentration (1 - $2 \mathrm{mM}$ ) of $\mathrm{AgNO}_{3}$.

\section{Separation of bacterial proteins}

Loopful of culture of bacteria was inoculated in $250 \mathrm{ml}$ conical flask containing $100 \mathrm{ml}$ sterile N-broth growth. The inoc-ulated broth was incubated for $24-48 \mathrm{~h}$ at $300 \mathrm{C}$ in an incubator (CIS 24 BL, REMI, India) and sub-cultured. Bacterial cells were transferred to nutrient broth medium for cultivation of biomass at $300 \mathrm{C}$ for $48 \mathrm{~h}$. After incubation for about $48 \mathrm{~h}$, the culture was subjected for sonication to break the bacterial cells. Sonicated culture was centrifuged at a speed of $1,0000 \mathrm{rpm}$ at room temperature for 10 min. The Cell Free Supernatant containing bacterial proteins was harvested and used for the synthesis of AgNPs.

\section{Biosynthesis of Silver Nanoparticles}

Cell Free Supernatant of bacterial culture was added in $100 \mathrm{ml}$ aqueous solution of $1.5 \mathrm{mM} \mathrm{AgNO}$ and kept in incubator shaker (REMI, India) at $300 \mathrm{C}$ for $24 \mathrm{~h}$ at $120 \mathrm{rpm}$. The nanoparticles were obtained from reaction mixture by centrifuging (C30BL, REMI, India) at 12,000 rpm for $15 \mathrm{~min}$. The synthesized nanoparticles were then washed several times with de-ionized water and acetone. The washing process by centrifugation and for purification was repeated several times to avoid any impurity or any silver ions. The silver nanoparticles were dried for further characterizations and antibacterial activity assessment and dye decolonization test. A control set was also run in parallel which was incubated with sterilized Cell Free Supernatant in $100 \mathrm{ml}$ nitrate $(1.0 \mathrm{mM})$.

\section{Characterization of Silver Nanoparticles}

4.1 UV-Visible spectrometric analysis: The visible color change was observed for the reaction mixture containing silver nitrate(AgNO3) and Cell Free Supernatant(CFS). Sampling of solution was carried out regularly to monitor the bio reduction of silver nanoparticles. The UV spectrum of sampled solution $(3 \mathrm{ml})$ was measured by a UV spectrophotometer (Evolution 201, Thermo Fisher Scientific, USA) between wavelengths of $400-700 \mathrm{~nm}$. The spectrum with bands in this range has been associated with the surface Plasmon resonance of nano-sized silver metal, confirming the occurrence of silver nanoparticles in the culture solution.

4.2 Fourier- transform infrared (FTIR) spectroscopy analysis: The FTIR spectroscopy was carried out to recognize the function-

al groups present on the biosynthesized silver nanoparticles and responsible for the stability of the nanoparticle. The purified dried silver nanoparticles were mixed in potassium bromide in the ratio of 1:100 for FT-IR analysis. Infrared spectrum was recorded on

FT-IR spectrometer (NICOLET TM 6700, Thermo Scientific USA). All measurements were carried out in the range of 5,000 $450 \mathrm{~cm}-1$ at a resolution of $2.0 \mathrm{~cm}^{-1}$.

4.3 Electron Microscopy: The size and morphology of biosynthesized silver nanoparticles were characterized by Scanning elec-tron microscope (JEOL JSM-840, Japan) at accelerating voltage of $5 \mathrm{kV}$ with $100 \mathrm{~nm}$ point resolution. The elemental analysis of nanoparticles was carried out by energy dispersive $\mathrm{X}$-ray analysis (EDX) analyzer associated with scanning electron microscope (JEOL JSM-840, Japan), at an accelerating voltage of $20 \mathrm{kV}$. 


\subsection{Assessment of antibacterial potential}

4.4.1 Disc diffusion assay: Antimicrobial susceptibility test of the isolated organisms was done by disc diffusion method using the Kirby-Bauer technique ${ }^{[16]}$. The antibacterial activity of AgNps was evaluated against a strain of Staphylococcus aureus (designated as AN-2) available at laboratory of Department of Environmental Science, Babasaheb Bhimrao Ambedkar University Lucknow. All tests were performed on Mueller-Hinton agar. The surface of the medium was lightly and uniformly inoculated by a sterile cotton swab. Prior to inoculation, the swab stick was dipped into bacterial suspension having visually equivalent turbidity equal to $0.5 \mathrm{Mc}-$ Farland standards. Inoculated plates were incubated at $370 \mathrm{C}$ for 24 hours. On the next day, plates were read by taking measurement of zone of inhibition.

4.5 Decolourization assay of synthetic dyes: Decolourization assay was carried out quantitatively. Quantitative decolourization assay of methylene blue was carried out by incubating $0.5 \mathrm{ml}$ silver nano fluid with $50 \mathrm{ppm}$ dye solution containing $50 \mathrm{mM}$ sodium acetate buffer at $300 \mathrm{C}$. The reaction mixture contained, $50 \mathrm{ppm}$ dye solution, silver nano fluid in $50 \mathrm{mM}$ sodium acetate buffer $(\mathrm{pH}$
7.0). The reaction mixture was incubated at $300 \mathrm{C}$ in the dark for different time intervals $(2,4,6,8,10,12,24,28,30,32 \mathrm{hrs})$. The dye decolorization was measured by monitoring the decrease in absorbance maximum of methylene blue with a UV-Vis Spectrophotometer (Cary-100 Bio Varian, Australia). The decolourization was determined in terms of reduction in percent (\%) absorbance by using the following equation ${ }^{[17]}$.

$\mathrm{D}=100(\mathrm{C} 1-\mathrm{C} 2) / \mathrm{C} 1$

Where, $\mathrm{D}$ is the decolourization of the dye in percentage (\%), $\mathrm{C} 1$ is the initial concentration of the dye, and $\mathrm{C} 2$ is the concentration of the dye after incubation with enzyme and nano-fluid.

\section{Results}

\section{Isolation and Characterization of Bacteria}

Five (05) bacterial strains were isolated from composite soil samples collected from organic pollutant contaminated sites. A bacterial isolate, designated as AN-1 (Plate: 1), revealed growth in the presence of $\mathrm{AgNO}_{3}$ upto $1.0 \mathrm{mM}$, and was selected for further studies.

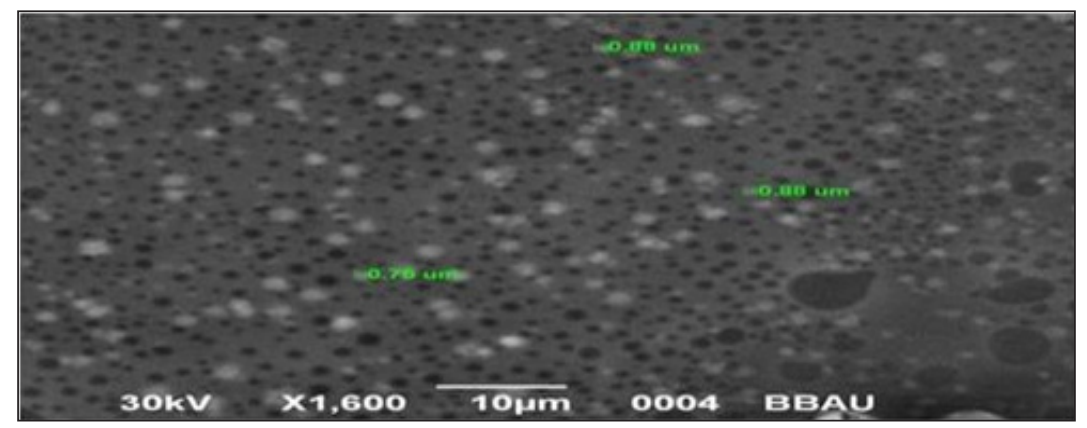

Plate: (1) A SEM micrograph of AgNPs synthesized from CFS of isolated bacterial strain

AN-1

Cellular morphology (Shape and arrangement of cells), and a Gram reactions were observed for the isolated bacterial strain AN-1 and was observed to be cocci, Gram-negative (Plate: 2) The shape of the colony was round and colour was pink. The isolated bacterial strain A1 was inoculated into nutrient broth and the growth profile was monitored for $0 \mathrm{~h}$ to $38 \mathrm{~h}$, at $300 \mathrm{C}$ at $180 \mathrm{rpm}$. The growth profile of the isolate is given in Figure: 1.

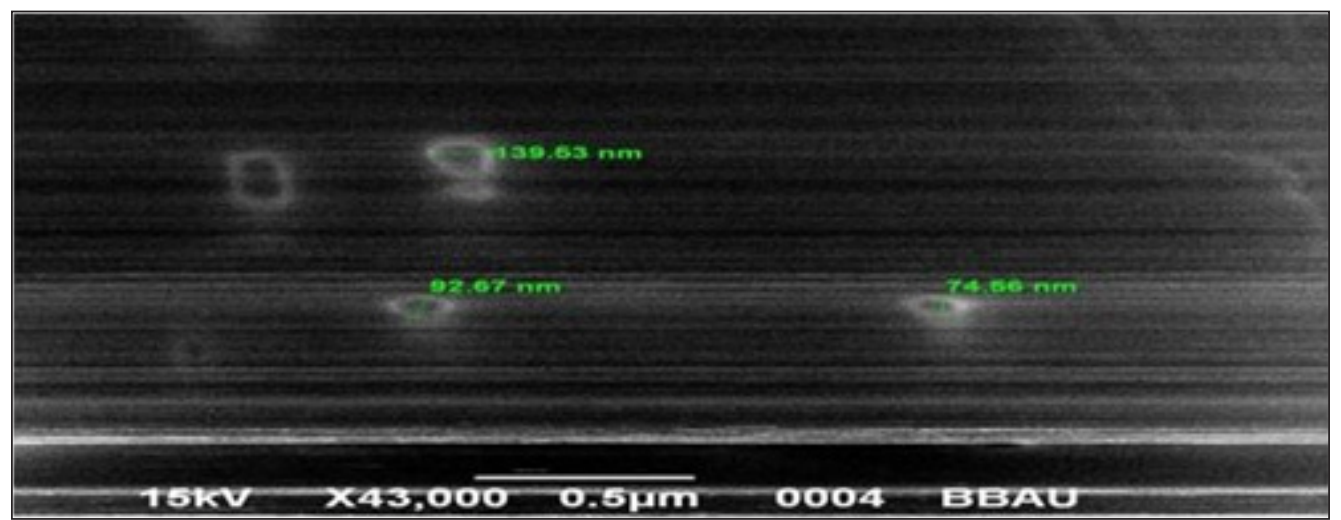

Plate: (2) SEM micrograph of AgNPs synthesize from CFS of inoculated bacterial strain A 


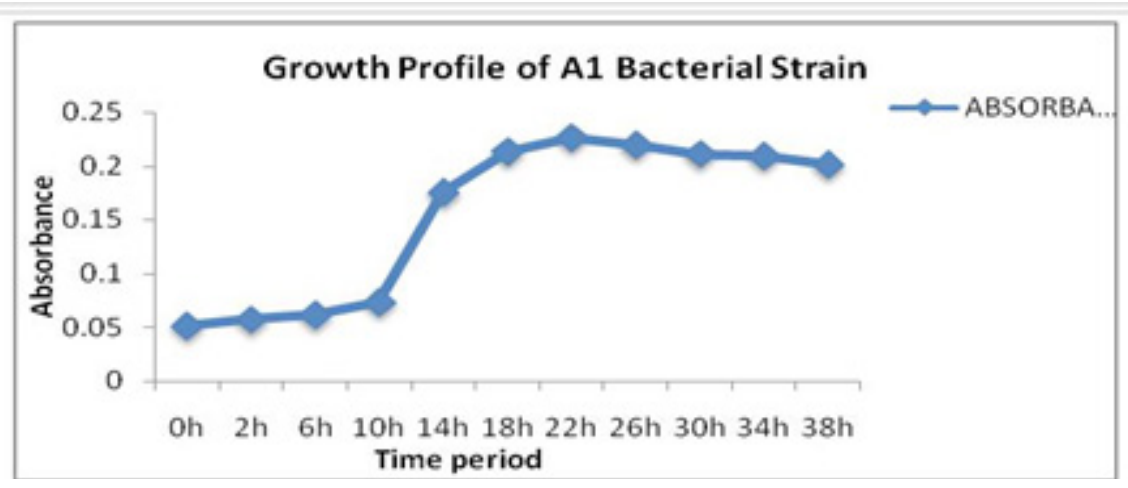

Figure: 1 Growth Profile of Bacterial Strain AN-1

Shows the qualitative growth at $24 \mathrm{~h}$ of incubation under standard culture condition. Results revealed a sigmoid curve, with a lag phase of $5 \mathrm{~h}$, followed by an exponential phase up to $22 \mathrm{~h}$ of incubation. Subsequently lag phase was observed until $38 \mathrm{~h}$.

\section{Biosynthesis of Silver nanoparticles:}

Subsequent to $24 \mathrm{~h}$ of incubation at $300 \mathrm{C}$ and $180 \mathrm{rpm}$, the cell suspension in Nutrient broth was centrifuged at $5000 \mathrm{rpm}$ to obtain the Cell Free Supernatant(CFS) which was collected for the synthesis of silver nanoparticles. The sample CFS was added to a separate reaction vessel containing silver nitrate $\left(\mathrm{AgNO}_{3}\right)$ at concentration of $1.5 \mathrm{mM}$. A control set was also run in parallel which contained heat killed supernatant Figure: 2. In case of reaction vessel containing $1.5 \mathrm{mM} \mathrm{AgNO} 3$ and Cell Free Supernatant, brown colour formation was observed as could be seen in Figure: 3 .

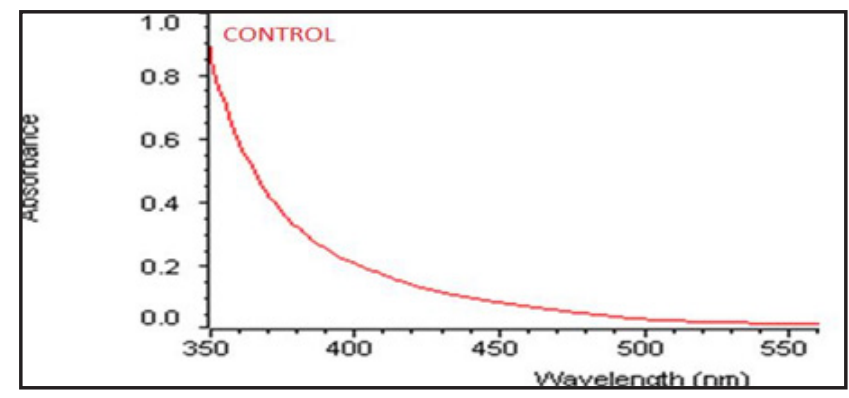

Figure 2: Absorption spectrum of control (Heat killed supernatant) showing no SPR peak.

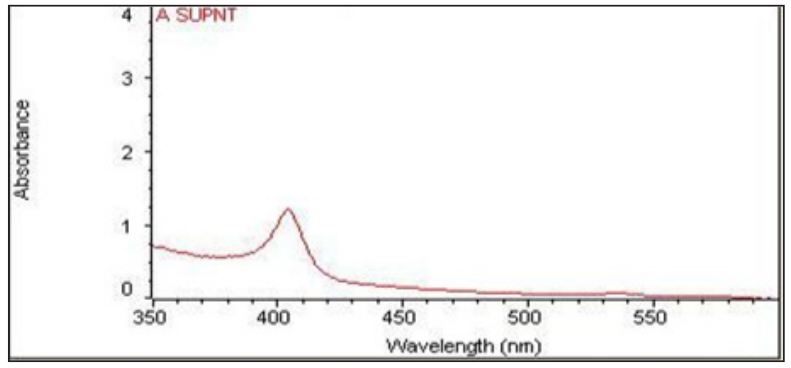

Figure 3: Absorption spectrum of silver nanoparticles exhibiting a strong broad peak at $405 \mathrm{~nm}$
Results further revealed an increase in brown colour formation with the period of incubation due to reduction of $\mathrm{Ag}+$ ions to $\mathrm{AgNO}_{3}$ control (without $\mathrm{AgNO}_{3}$ ) showed no colour formation in the culture supernatant when incubated under similar conditions. In the present study it was found that the colour of the sample containing cell free supernatant and $\mathrm{AgNO}_{3}$ increases with the incu-bation period, similar observation has also been reported by $^{[18]}$, who found that synthesis of silver nanoparticles also depends upon the incubation period of culture along with other cultural conditions.

\section{Characterization of silver nanoparticles}

3.1 UV-Visible Spectrometric Analysis: The appearance of brown colour in the sample revealed the formation of silver nanoparticles and an efficient reduction of $\mathrm{Ag}$ ions extracellularly. The distinct colour formation allowed the measurement of absorbance against a particular wavelength so as to confirm the formation of silver nanoparticles. The corresponding UV- Visible spectrum is shown in (Figure: 2) .The control sample containing heat killed supernatant revealed no evidence of absorbance in the range 350 $550 \mathrm{~nm}$. However the spectrum $(350-550)$ of the sample CFS containing AgNO3 $(1.0 \mathrm{mM})$ after an incubation of $24 \mathrm{~h}$ revealed sharp peak at $410 \mathrm{~nm}$. It is well established that samples exposed to $\mathrm{AgNO} 3$ solution shows wide spectrum range around 390 $410 \mathrm{~nm}^{[19]}$. Hence the presence of a peak at $405 \mathrm{~nm}$ (Figure: 4) indicated the aggregation of silver nanoparticles in the solution. The spectrum with bands in the above mentioned range (390 $410 \mathrm{~nm}$ ) has been associated with the surface plasmon resonance of nano size silver metal, conforming the occurrence of silver nanoparticles in the culture medium.

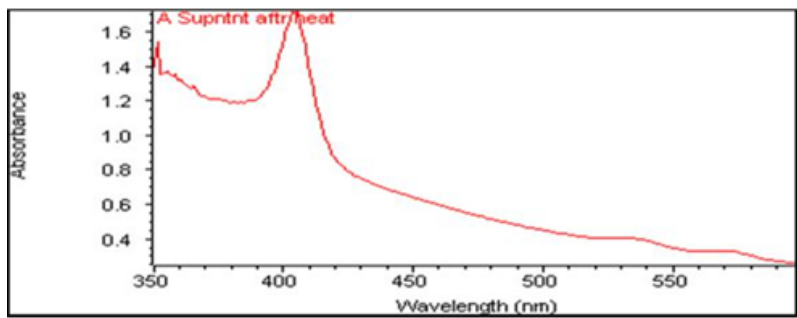

Figure 4: Absorption spectrum of silver nanoparticles exhibiting a strong broad peak at $405 \mathrm{~nm}$ after heating of the CFS sample containing $\mathrm{AgNO}_{3}$. 
The silver nitrate $\left(\mathrm{AgNO}_{3}\right)$ added CFS supernatant was incubated at $1000 \mathrm{C}$ for 25 seconds in a water bath, so as to assess the synthesis of silver nanoparticles under high temperature.

Results (Figure: 4) revealed the change in color from pale grey to light brown and then brown after 25 seconds at $1000 \mathrm{C}$, indicating the formation of SNPs. This color arises due to surface Plasmon vibrations in the metal nanoparticles ${ }^{[20]}$.

3.2 Fourier- transform infrared (FTIR) spectroscopy analysis: Fourier transform infrared (FTIR) spectral measurements were carried out to identify the potential biomolecules in CFS samples of the bacterial strain $\mathrm{A} 1$, containing $\mathrm{AgNO}_{3}$ and control (without $\mathrm{AgNO}_{3}$ ), which is responsible for reducing and capping the bio reduced silver nanoparticles. The IR spectra provided information about the local molecular environment of the organic molecules on the surface of nanoparticle.

In the present work, FTIR spectral measurements were carried out to identify the potential biomolecules in cell free su-pernatant sample, which is responsible for reducing and capping the bio reduced silver nanoparticles. Fourier transform infrared spectroscopy (FTIR) is a technique which is used to analyze the chemical composition of many organic chemicals, polymers, paints, coatings, adhesives, lubricants, semiconductor materials, coolants, gases, biological samples, inorganics, and minerals. FTIR can be used to analyze a wide range of materials in bulk or thin films, liquids, solids, pastes, powders, fibres, and other forms. FTIR analysis can give not only qualitative (identification) analysis of materials, but, with relevant standards, can be used for quantitative (amount) analysis. FTIR can be used to analyze samples up to $\sim 11$ millimetres in diameter and either measure in bulk or the top $\sim 1$ micrometer layer. (Figure: 5 )

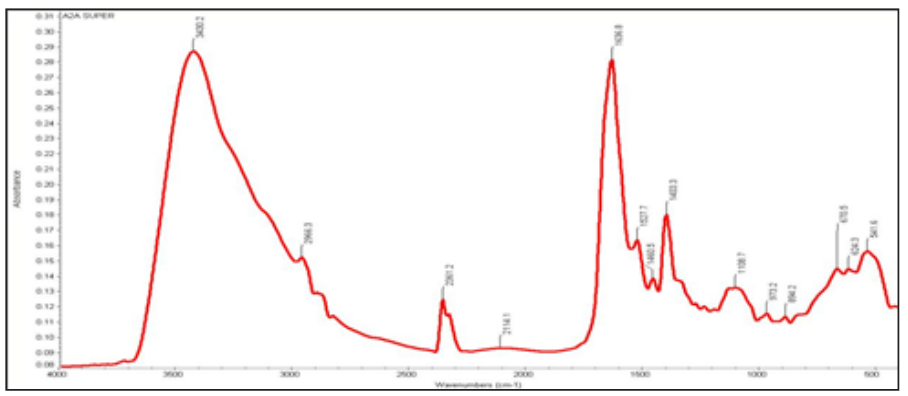

Figure 5: FTIR spectrum of green synthesized silver nanoparticles using AN-1, CFS sample (containing $\mathrm{AgNO}_{3}$ ).

The results of FTIR analysis of this study show different stretches of bonds shown at different peaks. In the CFS sample, silver nanoparticles peaks were observed at $3430.2-\mathrm{N}-\mathrm{H}$ stretch, 2966.3 - single aldehyde, 2361.2- $\mathrm{C}-\mathrm{H} ; \quad \mathrm{O}-\mathrm{H}, \quad 2114.1-$ $\mathrm{C} \equiv \mathrm{C} 1638.8-\mathrm{C}=\mathrm{C}$ and $1108.7-\mathrm{C}=\mathrm{O}$ shows the peaks near $3430 \mathrm{~cm}-1,2966 \mathrm{~cm}^{-1}$, and $2114 \mathrm{~cm}^{-1}$ assigned to $\mathrm{OH}$ stretching and aldehy-dic $\mathrm{C}-\mathrm{H}$ stretching, respectively. The sharp band at $1638 \mathrm{~cm}^{-1}$ corresponds to amide I arising due to carbonyl stretch in proteins. The peak at $1108 \mathrm{~cm}^{-1}$ corresponds to $\mathrm{C}-\mathrm{N}$ stretching vibration of the amine. The peak near $894 \mathrm{~cm}^{-1}$ assigned to $\mathrm{C}=\mathrm{CH} 2$ and the peaks near $670 \mathrm{~cm}^{-1}$ and $624.3 \mathrm{~cm}^{-1}$ assigned to $\mathrm{CH}$ out of plane bending vibrations are substituted ethylene systems $\mathrm{CH}=\mathrm{CH}(\mathrm{cis})^{[21,22]}$. FTIR spectra of silver nanoparticles exhibited prominent peaks at 2,966, 1,638, and $1,403 \mathrm{~cm}^{-1}$. The spectra showed sharp and strong absorption band at $1,638.8 \mathrm{~cm}^{-1}$ assigned to the stretching vibration of $(\mathrm{NH}) \mathrm{C}=\mathrm{O}$ group. The band 1,403 developed for $\mathrm{C}-\mathrm{C}$ and $\mathrm{C}-\mathrm{N}$ stretching; presence of the sharp peak at $2,927 \mathrm{~cm}^{-1}$ was assigned to $\mathrm{C}-\mathrm{H}$ and $\mathrm{C}-\mathrm{H}$ (methoxy compounds) stretching vibration. However, the FTIR analysis of the CFS control sample (devoid of AgNO3) did not show the signature peaks T 2,966, 1,636, and 1,403 $\mathrm{cm}^{-1}$ in (Figure: 6).

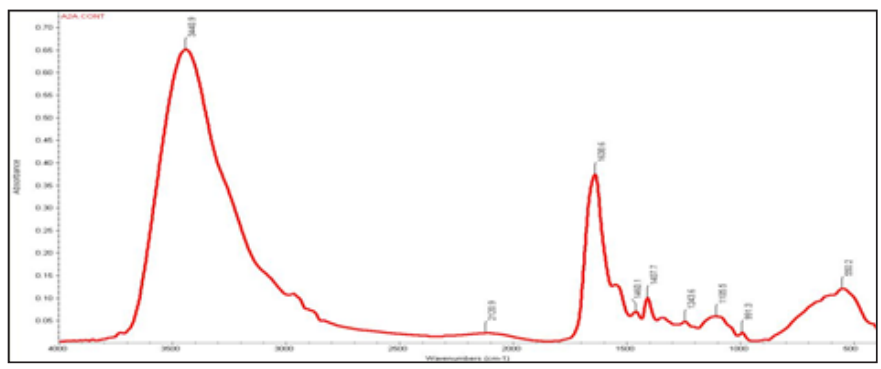

Figure 6: FTIR spectrum of heat killed supernatant CFS of bacterial isolate $\mathrm{AN}-1$ (Control).

3.3 Electron Microscopy: SEM analysis shows high-density AgNPs synthesized in CFS samples of the bacterial strain A1, con-taining AgNO3. It was shown that relatively spherical AgNPs were formed with diameter of $74.56 \mathrm{~nm}$ to $92.67 \mathrm{~nm}$. The SEM image of silver nanoparticles was due to interactions of hydrogen bond and electrostatic interactions between the bioorganic capping molecules bound to the AgNPs ${ }^{[21]}$. The larger silver particles may be due to the aggregation of the smaller ones, due to the SEM measurements.

3.4 Decolorization of methylene blue: The potential of silver nanoparticles in decolorization of dye was demonstrated using the dye methylene blue. The decolorization of methylene blue was carried out in the presence of silver nanoparticles at different time intervals up to 32 minutes. At specific time intervals, aliquots of $3 \mathrm{ml}$ suspension were filtered and used to measure the decoloriza-tion of the dye using UV-Vis spectrophotometer at different wavelength. Decolourization of the dye was calculated by the absor-bance value at $660 \mathrm{~nm}$ (specific for the dye). (Figure: 7 and Figure: 8) Results revealed the decreased peaks for methylene blue in the absorption spectrum, at different time intervals. The absorption spectrum of the dye methylene blue is given in which shows a strong sharp peak at $660 \mathrm{~nm} 0.65(\mathrm{OD})$. Upon decolorization the peak at $660 \mathrm{~nm}$ was found to reduce significantly $0.011(\mathrm{OD})$. The decolourization efficiency of silver nanoparticles was calculated as $85 \%$ at $32 \mathrm{~h}$. The decolourization was found to increase with an increase in the exposure time of dye-silver nanoparticles complex given in Figure: 9. Overall results revealed that absorption peak for methylene blue was centered around $660 \mathrm{~nm}$ in visible region of the spectrum which diminished and finally disappeared while increasing the reaction time, which indicates silver nanoparticle induced decolourization of the dye. 


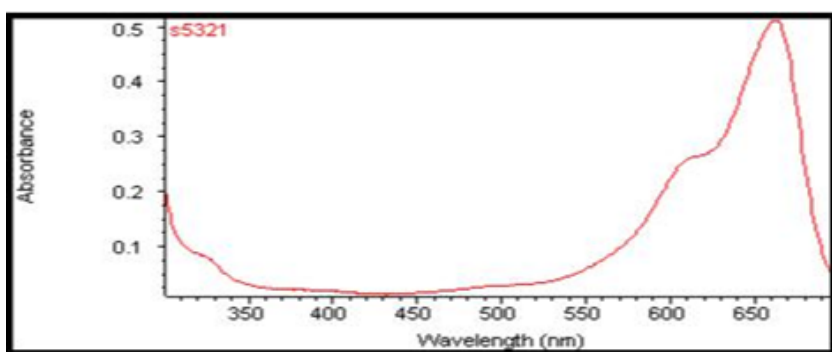

Figure 7: Absorption spectrum of Methylene blue (Control).

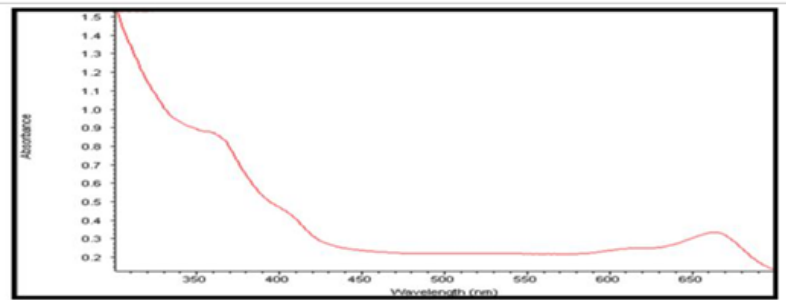

Figure 8: Absorption spectrum of methylene blue solution along with CFS containing $\mathrm{AgNO}_{3}$ nanoparticles.

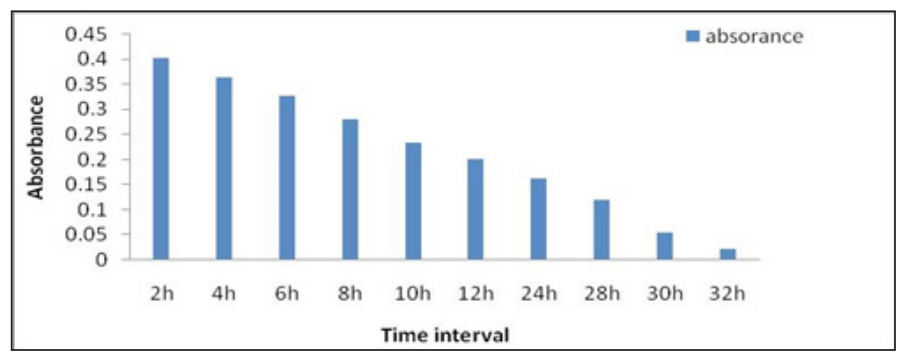

Figure 9: Degradation of methylene blue at different time intervals.

3.5 Assessment of antibacterial potential: The antibiotic activity of AgNPs was investigated against another bacterium (a gram positive, rod) isolate from the organic pollutant contaminate site (designated as strain AN-2) using well diffusion method.

Results revealed an inhibition zone of $3.5 \mathrm{~mm}$ and $3.1 \mathrm{~mm}$ around the two wells containing SNP solution. This shows the SNPs synthesized from the isolated bacterial strain A1 bears antimicrobial property.

\section{Conclusion}

There has been an exponential increase in interest in biological synthesis of AgNPs due to their wide spread applications in medical, pharmaceuticals, biotechnology including nanobioremediation for environmental clean-up. In the present study, AgNPs were synthesized following an ecofriendly and convenient method using Cell Free Supernatant(CFS) of isolated bacterial strain A1, at ambient temperature. Bacterial biomass was used as a reducing agent for the synthesis of silver nanoparticles from silver nitrate(AgNO3). Green synthesized silver nanoparticles are confirmed by colour change which was monitored quantitatively by UV-Vis spectroscopy at $410 \mathrm{~nm}$. Further characterization with SEM analysis revealed the spherical, polydisperse AgNPs of particle size ranging from 74.56 to $92.67 \mathrm{~nm}$. FTIR showed the structure and the signature bands of the synthesized nanoparticles, at $2,966,1,636$, and $1,403 \mathrm{~cm}^{-1}$. Significant antimicrobial activity of the green synthesized silver nanoparticles was observed. Synthesized silver nanoparticles revealed the potential towards the decolorization of the test dye, methylene blue. Cell free supernatant (CFS) of the isolated bacterial strain A1 can be used as an eco friendly agent for synthesis of nanoparticles which show excellent catalytic activity against dye molecules and hence can be used in water purification systems and dye effluent treatment.

\section{References}

[1] Feynman, R. There's plenty of room at the bottom. (1991) Sci 29: 1300- 1301 .

${ }^{\text {[2] }}$ Mazur, M. Electrochemically Prepared Silver Nanoflakes and Nanowires. (2004) J Electrochem Soc 6(4): 400-403.

${ }^{[3]}$ Mornet, S., Vasseur, S., Grasset, F., et al. Magnetic nanoparticle design for medical diagnosis and therapy. (2004) J Mater Chem 14: 2161-2175.

[4] Tratnyek, P.G., Johnson, R.L. Nanotechnologies for environmental cleanup. (2006) Nanotoday 1(2): 44-49.

${ }^{[5]}$ Rai, M.K., Deshmukh, S.D., Ingle, A.P., et al. Silver nanoparticles: the powerful nanoweapon against multidrug-resistant bacteria. (2012) J App Microbiol 112(5): 841-852.

[6] Ajitha, B., Reddy, A.K., Reddy, P.S. Enhanced antimicrobial activity of silver nanoparticles with controlled particle size by $\mathrm{pH}$ variation. (2015) Pow Tech 269: 110-117.

[7] Jain, K.P., Huang, X., El-Sayed, H.I., et al. Noble Metals on the Nanoscale: Optical and Photothermal Properties and Some Applications in Imaging, Sensing, Biology, and Medicine. (2008) Acc Chem Res 41: 1578-1586.

[8] Ferrari, M. Cancer nanotechnology: opportunities and challenges. (2005) Nat Rev Cancer 5(3): 161-171.

${ }^{[9]}$ Mohanta,Y.K., Behera, S.K. Biosynthesis, characterization and antimicrobial activity of silver nanoparticles by Streptomyces sp. SS2. (2014) Bioprocess Biosy Eng 37(11): 2263-2269.

[10] Priyaragini, S., Veena, S., Swetha, D., et al. Evaluating the effectiveness of marine actinobacterial extract and its mediated titanium dioxide nanoparticle in the degradation of azo dyes. (2014) J Environ Sci 26(4): 775-782.

[11] Wang, H., Zhang, W., Zhao, J., et al. Rapid decolorization of phenolic azo dyes by immobilized laccase with $\mathrm{Fe} 3 \mathrm{O} 4 / \mathrm{SiO} 2$ nanoparticles as support. (2013) Ind Eng Chem Res 52(12): 44014407.

[12] Tiwari, S., Rai, P., Yadav, S.K., et al. A novel thermotolerant Pediococcus acidilactici B-25 strain for color, COD, and BOD reduction of dis-tillery effluent for end use applications. (2013) Environ Sci Pollut Res Int 20(6): 4046-4058.

[13] Rizwan, M.D., Singh, M., Mitra, C.K., et al. Ecofriendly Application of Nanomaterials: Nanobioremediation. (2014) J 
Nanoparticles.

${ }^{[14]}$ Karthik, L., Kumar, G., Kirthi, A.V., et al. Streptomyces sp. LK3 mediated synthesis of silver nanoparticles and its biomedical application. (2014) Bioprocess Biosys Eng 37(2): 261-267.

${ }^{[15]}$ Duran, N., Marcato, P., Alves, O., et al. Mechanistic aspects of biosynthesis of silver nanoparticles by several Fusarium oxysporum strains. (2005) J Nanobiotechnology 3: 8.

[16] Bauer, A.W., Kirby, W.M., Sherris, J.C., et al. Antibiotic susceptibility testing by a standardized single disk method. (1966) Am J Clin Pathol 45(4): 493-496.'

${ }^{[17]}$ Murugesan, K., Nam, I.H., Kim, Y.M., et al. Decolorization of reactive dyes by a thermostable laccase produced by Ganoderma lucidum in solid state culture. (2007) Enz Mic Tech 40(7): 16621672.

[18] Gurunathana, S., Kalishwaralala, K., Vaidyanathana, R., et al. Biosynthesis, Purification and Characterization of Silver
Nanoparticles using Escherichia coli. (2009) Colloids Surf B Biointerfaces 74(1): 328-335.

[19] Natarajan, K., Selvaraj, S., Ramachandra, M.V. Microbial production of silver nanoparticles. (2010) Digest J Nanomaterials Biostructures 5(1): 135-140.

${ }^{[20]}$ Shankar, S.S., Ahmad, A., Sastry, M. Germanium leaf assisted biosynthesis of silver nanoparticles. (2003) Biotechnol Prog 19(6): 1627- 1631 .

${ }^{[21]}$ Priya, M.M., Selvia, B.K., Paul, J.A.J. Green synthesis of silver nanoparticles from the leaf extracts of euphorbia hirta and nerium indicum. (2011) Digest J Nanomaterials Biostructures 6(2): 869 877

[22] Devaraj, P., Kumari, P., Aarti, P.C., et al. Synthesis and Characterization of Silver Nanoparticles Using Cannonball Leaves and Their Cytotoxic Activity against MCF-7 Cell Line. (2013) J Nanotechnol 